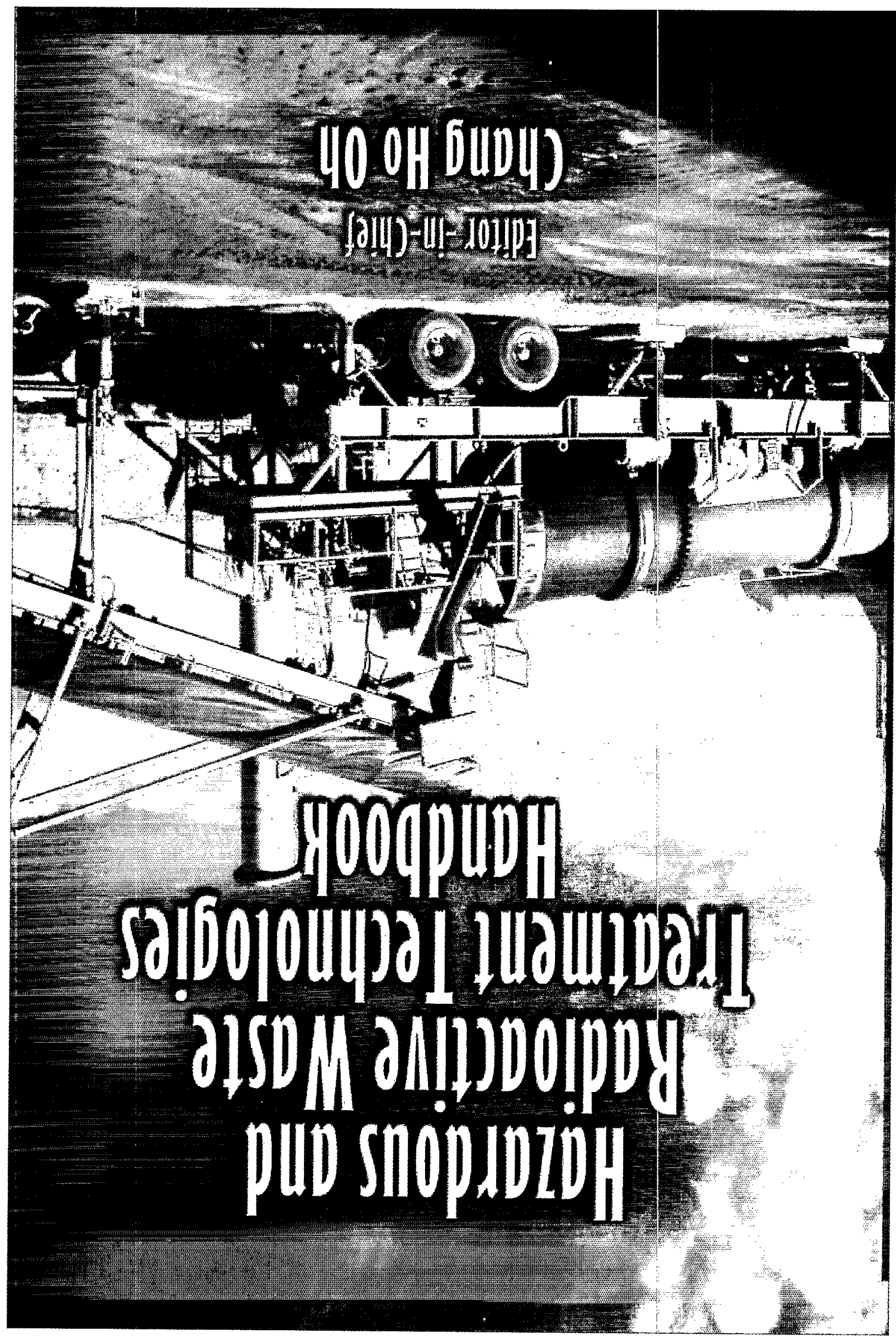




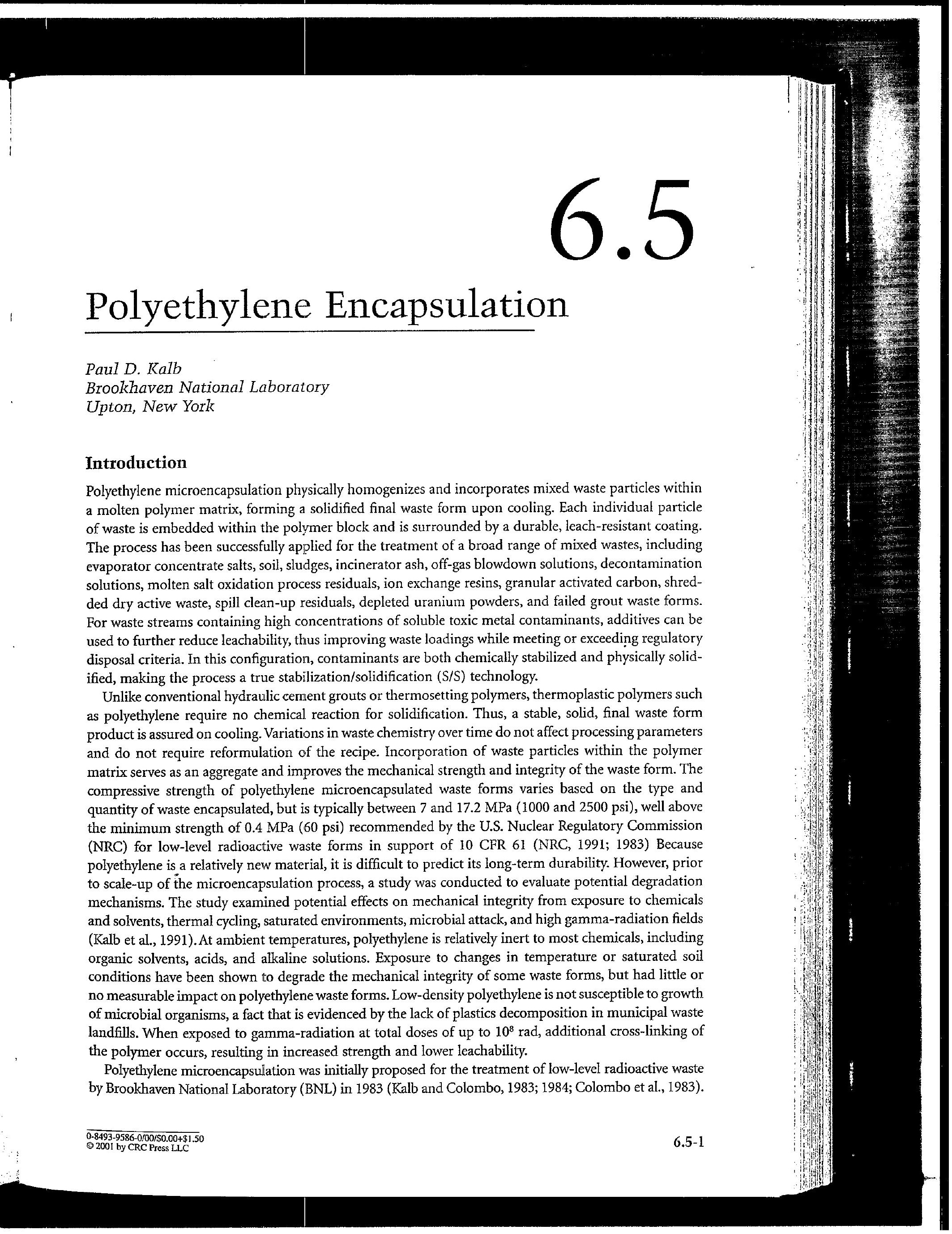


Since then, under support from the U.S. Department of Energy (DOE), the technology has progressed steadily from proof-of-principle testing and laboratory-scale development, through pilot-and productionscale demonstration, and finally on to commercial deployment. In addition to the development activities conducted at BNL, the DOE has supported several years of process testing at Rocky Flats Environmental Technology Site (RFETS) (Faucette et al., 1994) As the need for treatment of mixed wastes emerged in the late 1980s, application of the technology for hazardous wastes was also established. Following numerous bench-scale processing studies, final waste form product performance testing (Fuhrmann and Kalb, 1996; Lageraaen et al., 1995; Kalb, 1983) and studies investigating long-term durability (Kalb et al., 1991; 1993) a full-scale demonstration was conducted in 1994 (Kalb et al., 1996). Using a production-scale extruder capable of processing $2000 \mathrm{lb} / \mathrm{hr}$, the demonstration successfully confirmed all aspects needed for a fully integrated processing system, including pretreatment of aqueous wastes, precise feed metering, extrusion processing, online quality control monitoring, and computerized process control. Figure 6.5 .1 is a photograph of the full-scale polyethylene encapsulation extrusion process installed at BNL. Following successful development of the extrusion-based microencapsulation process, an alternative processing method using a kinetic mixer was developed and demonstrated (Lageraaen et al., 1997). A pilot-scalc kinetic mixing process for polyethylene microencapsulation is shown in Figure 6.5.2. Each method has advantages for specific waste types and propertics. BNL currently holds three patents for the polyethylene microencapsulation process, with several others pending (Kalb and Colombo, 1997; 1998; 1999). In 1997, BNL issued a commercialization license to Envirocare of Utah, where polyethylene microencapsulation has been deployed to treat DOE and commercially generated mixed wastes using both kinetic mixing and extrusion processing. Various polyethylene microencapsulation processing options, selection of optimal polymer feedstock, pretreatment requirements and options, critical process parameters and formulations, and typical final waste form performance results are discussed in this chapter section.

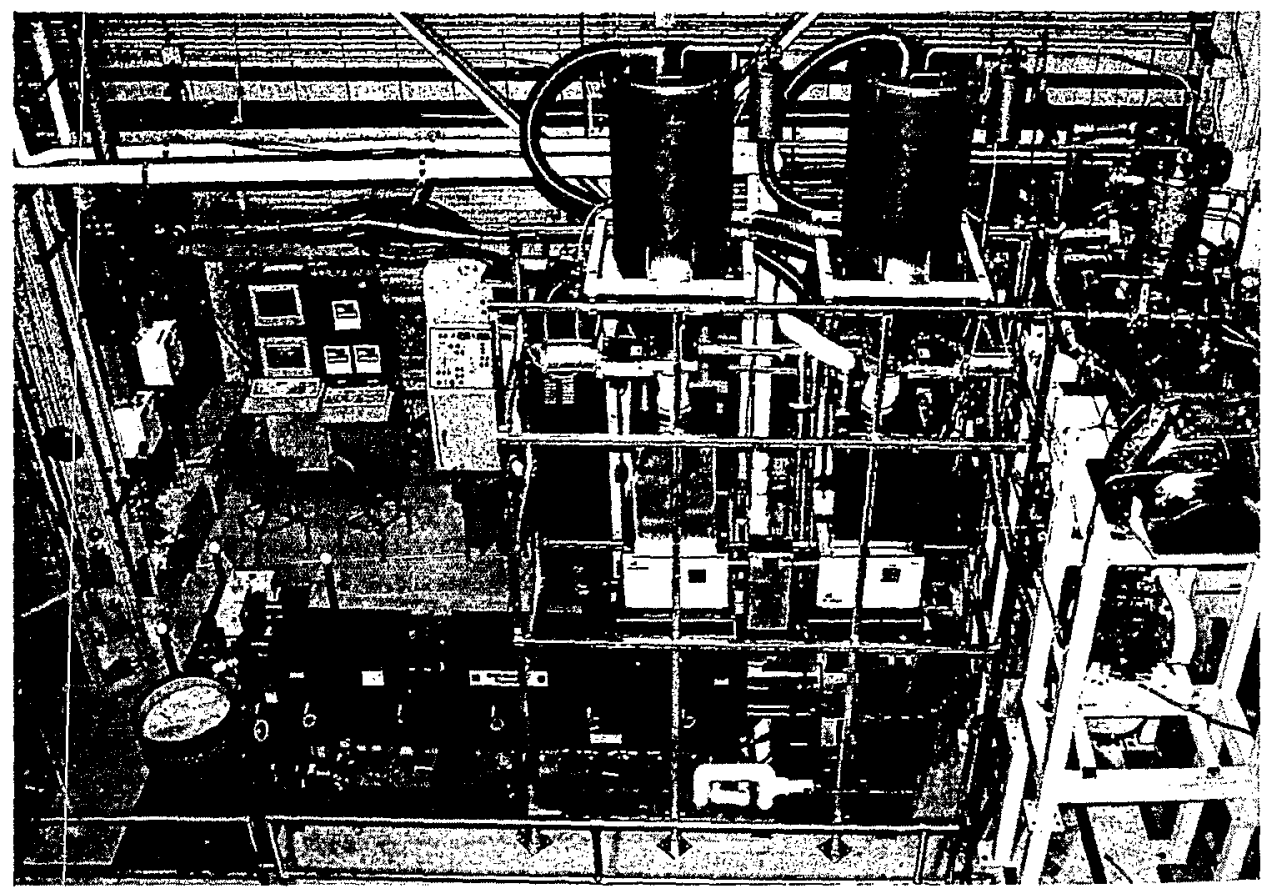

FIGURE 6.5.1 Full-scale polyethylene encapsulation extrusion process.

For waste streams that contain large particles not conducive to microencapsulation processing (e.g., pieces of lead, large debris with a particle size $>60 \mathrm{~mm}$ ), a related technology known as polyethylene macroencapsulation was developed (Kalb et al., 1995). For macroencapsulation, the waste is consolidated or 


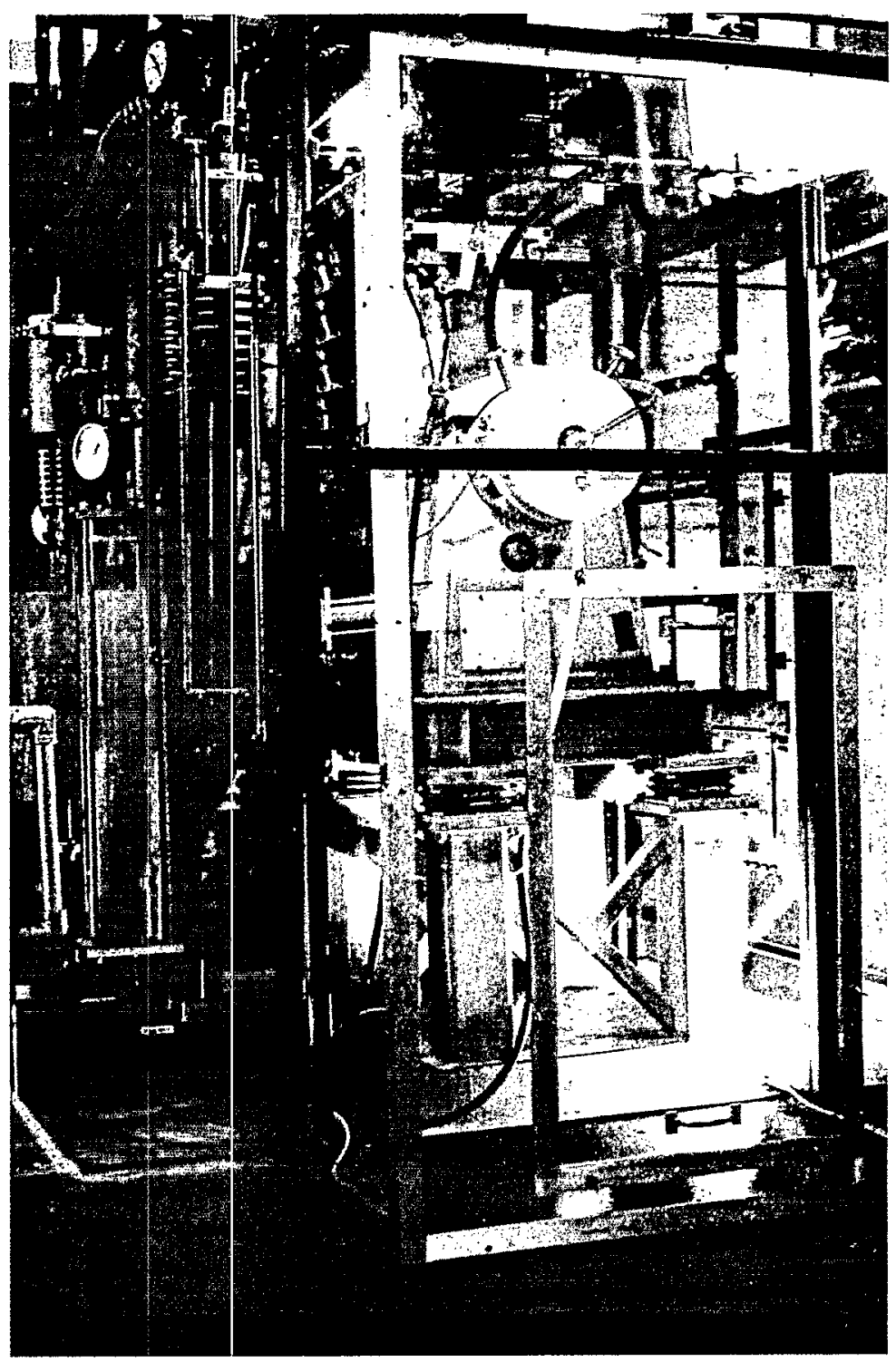

FIGURE 6.5.2 A pilot-scale kinetic mixing process for polyethylene microencapsulation.

compacted and a clean layer of molten polymer is extruded around it to form a thick, durable, leach-resistant barrier around the entire waste package. The U.S. Environmental Protection Agency (EPA) has established macroencapsulation as the Best Demonstrated Available Technology (BDAT) for these types of wastes. Thus, for these waste streams, the treatment vendor is not required to demonstrate compliance with specific performance criteria for treated macroencapsulated waste form packages. With DOE supported technology transfer assistance provided by BNL, Envirocare has also implemented polyethylene macroencapsulation and has successfully treated over a million pounds of mixed waste lead and debris to date. Macroencapsulation treatment techniques and applications are also discussed in detail in this chapter section.

\section{Equipment Selection}

Several types of processing techniques have been explored for polyethylene encapsulation (Patel et al., 1995). Selection of the optimal system must consider the type, properties, and volume of waste to be 
treated; equipment, operation, and maintenance costs; ease of operation; and performance requirements. Versatility is also an important consideration when selecting polyethylene encapsulation process equipment. For example, extruders can be used for both microencapsulation or macroencapsulation, and kinetic mixers can, in some cases, eliminate the need for pretreatment. Each type of equipment has advantages and limitations. When operated for microencapsulation, extrusion processing is limited by the amount of moisture or other volatiles present in the waste. As the mixture of plastic and waste is heated in an extruder, gases generated through vaporization of moisture or organics may become trapped within the viscous molten polymer and create an undesirable foany product. Some extruders are equipped with a venting zone between the transition and metering zones, which can remove trapped air and volatile gases. Kinetic mixers do not trap vapors as readily as extruders, but operate in batch mode rather than continuous processing achieved by extrusion.

\section{Single-Screw Extruders}

The first successful application of polyethylene microencapsulation of waste was conducted using a singlescrew extruder, the most commonly used technique in the plastics industry. In fact, extrusion has been routinely used for plastics processing for more than 60 years, confirming its reliability and ease of operation. Extrusion is accomplished in a heated cylindrical barrel in which an augered screw conveys and mixes the material. Figure 6.5 .3 is a schematic view of a typical plastics extruder. The process consists of three basic steps: feed, transition, and metering. In the feed zone, polyethylene pellets or powder are gravity-fed to the feed throat. Fillers, including waste and additives, can be introduced with the polymer or added upstream through a mechanical "crammer" feeder. Figure 6.5.4 is a photograph of a typical extruder screw. As the unmelted materials are moved forward by the rotating auger, prcssure builds due to decreasing volume of the screw channels. In the transition zone, heat to melt the plastic is gradually introduced by a series of external band heaters and, to a lesser degree, by frictional heat generated by the polymer. Thermocouples in the barrel monitor temperatures in each zone, which are precisely controlled by solid-state proportional-integral-derivative (PID) controllers. Excess heat created by frictional energy is removed by cooling fans or by circulating liquid coolant. Mixing occurs as the materials are further compressed by the decreasing channel volume and the shearing forces generated by the rotating screw. Several types of screw designs, shown in Figure 6.5.5, are available to enhance mixing in singlescrew extruders, although adequate mixing for microencapsulation has been established with basic metering screws. Some extruders are equipped with a venting zone between the transition and metering zones that removes trapped air or volatile gases generated during processing. A sudden increase in the channel volume reduces pressure, allowing vacuum to be applied through a vent in the barrel. A vented

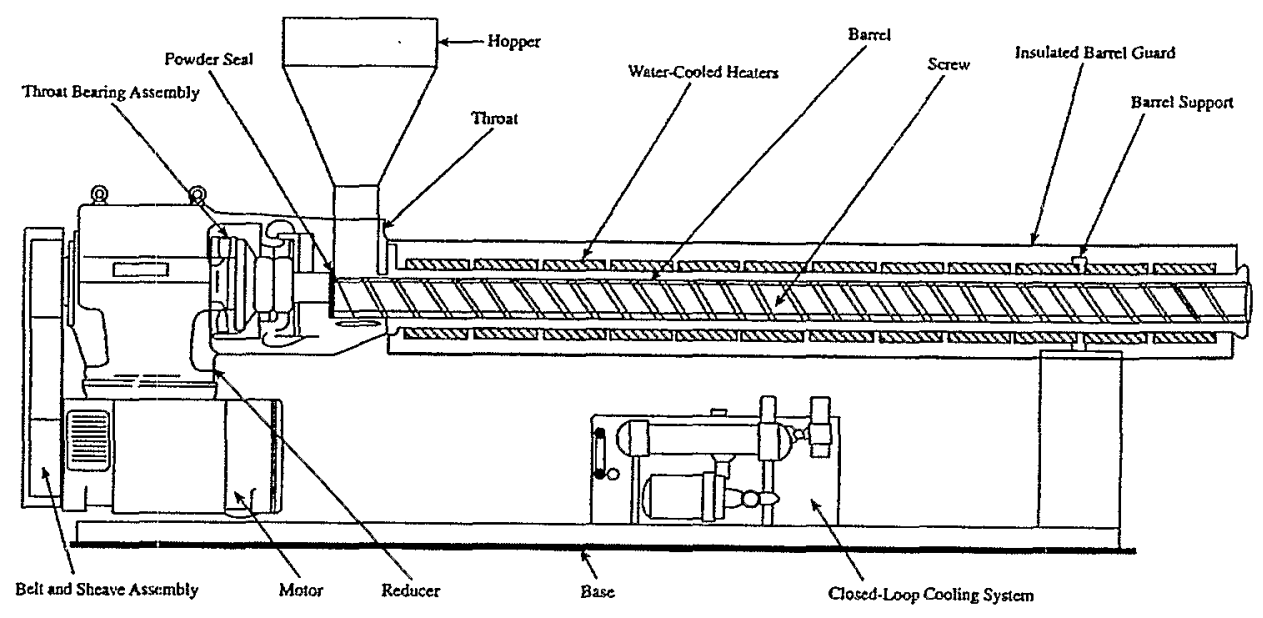

FIGURE 6.5.3 Schematic of typical plastics extruder. 


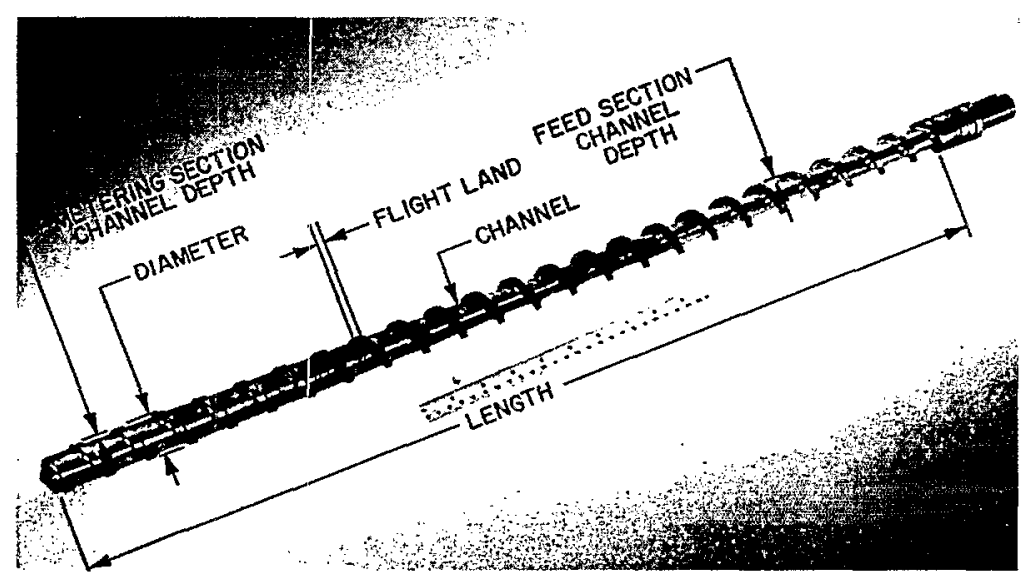

FIGURE 6.5.4 A typical extruder screw.

screw design is highly recommended for microencapsulation applications because wastes typically contain some residual moisture or other volatile gases that, if not removed, get trapped within the plastic yielding an undesirable foamy product. Finally, pressure is increased as the materials are further compressed in the metering zone in preparation for discharge through an output die.

\section{Twin-Screw Extruders}

Twin-screw extruders, equipped with two side-by-side screws, have been used in the plastics industry for difficult compounding applications, such as the addition of glass fibers or other bulky fillers. They were initially applied for waste encapsulation in the mid-1970s using bitumen as the binder matrix (Werner and Pfleiderer Co., 1976). A production-scale twin-screw bitumen processing system was installed at the Palisades Nuclear Power Station in Michigan to treat aqueous borated salts. Twin-screw processing was successfully applied for polyethylene microencapsulation at RFETS (Faucette et al., 1994). Various configurations are available, including co- and counter-rotating, and intermeshing and non-intermeshing screws, as shown in Figure 6.5.6. The action of the two screws can provide increased shear and improved pumping for those materials that are difficult to feed. Each design has unique mixing and flow characteristics that must be balanced, depending on the specific engineering requirements. For example, counter-rotating, intermeshing screws provide improved mixing control, increased shear, and conveying properties. Non-intermeshing, counter-rotating designs sacrifice the degree of shear, but can deliver higher throughputs. Due to improved dispersive mixing, twin-screw extruders may be able to more readily process fine particles compared with single-screw extruders. Larger particles, however, may be more problematic for twin-screws due to tight clearances between screw flights. While twin-screw extruders have been successfully demonstrated at bench scale for polyethylene microencapsulation (Faucette et al., 1994), there are no data indicating improved processing or performance of final waste forms compared with those produced by single-screw processing.

Vented twin-screw extruders are also available. The twin-screw extruder used at Palisades Nuclear Power Station was equipped with multiple vacuum ports at several stages along the barrel to remove excess volatiles. This enabled gradual feeding of aqueous wastes, which were evaporated within the heated barrel. Water vapor was collected and condensed before being trapped within the thermoplastic polymer. However, this design was limited by the ability of the extruder to drive off and collect the moisture, and as a result, the overall process rates were prohibitively slow. Thus, for either single- or twin-screw microencapsulation applications, pretreatment of aqueous wastes using process equipment specifically designed for moisture removal (e.g., vacuum dryers) is recommended. 

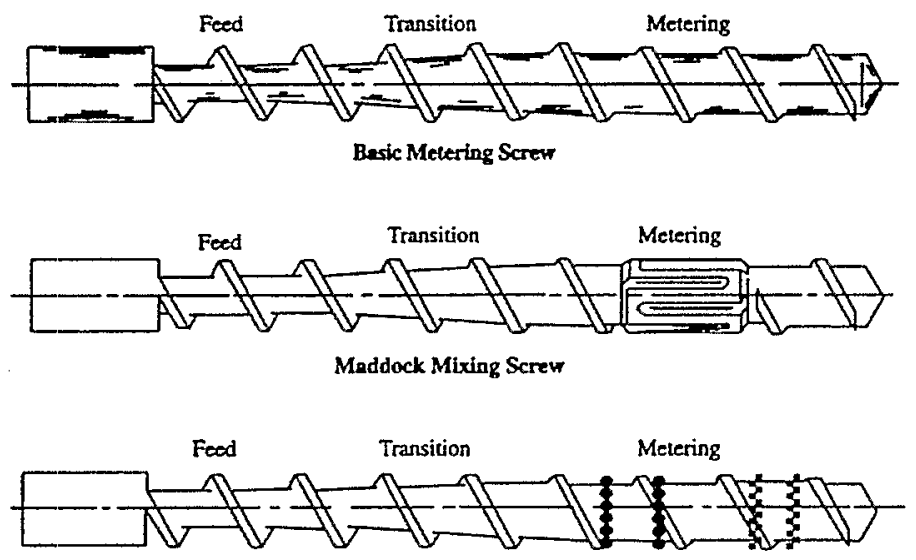

Pin Mlixing Screw
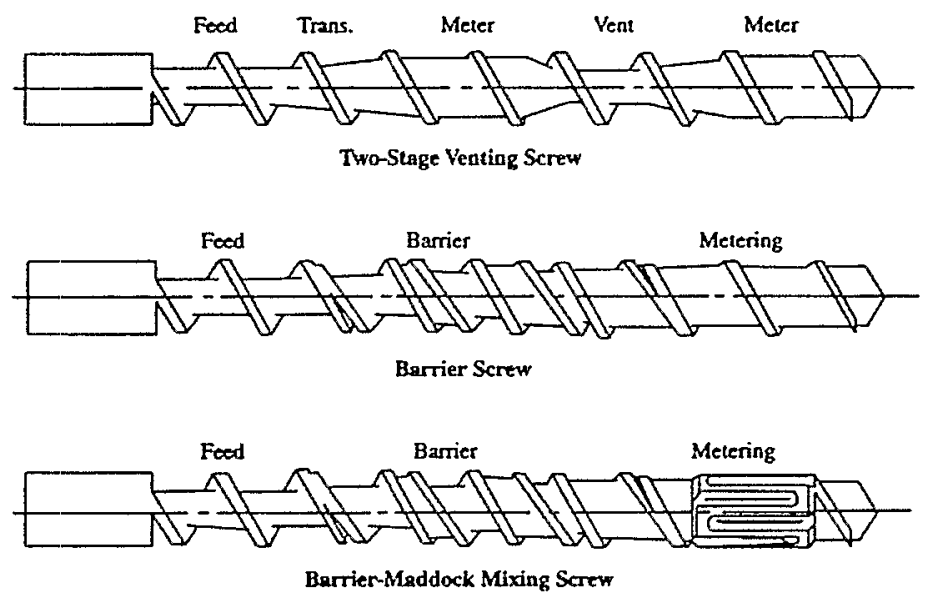

FIGURE 6.5.5 Various screw types available for single-screw extruders.

\section{Thermokinetic Mixers}

Unlike extruders, thermokinetic mixers (also known as kinetic mixers) do not rely on external thermal energy to melt the plastic. Instead, polymer melting occurs due to the frictional (kinetic) energy that results from high-speed, high-shear mixing. They also differ from extruders in that they operate in batch, rather than continuous mode. This allows for a greater degree of mixing than can be achieved with extrusion techniques. The high-shear mixing occurs through the action of a rapidly rotating rotor with offset blades (blade tip speeds are typically up to $45 \mathrm{~m} / \mathrm{s}$ ) in a relatively small mixing chamber. Materials are loaded through a gravity-fed hopper controlled by a slide or pinch gate, and are then transferred to the mixing chamber by an auger mounted on the rotor. Melting or fluxing of the polymer occurs rapidly, typically in 15 to $30 \mathrm{~s}$ and can be monitored by infrared temperature probe, predetermined batch time, or the change in vibration and sound that occurs as the molten plastic mass is formed. The pitch of the mixing blades moves the material toward the pneumatically controlled discharge gate, which allows the molten material to exit the mixer.

Because of the rapid increase in temperature and the design of the batch-mixing chamber, volatile gases can be removed before being trapped within the viscous polymer. This method allows the successful processing of wastes with higher moisture or volatile organic constituent (VOC) concentrations (up to about 35 wt\%) without pretreatment. Current kinetic mixer processing vessels are not designed to hold 

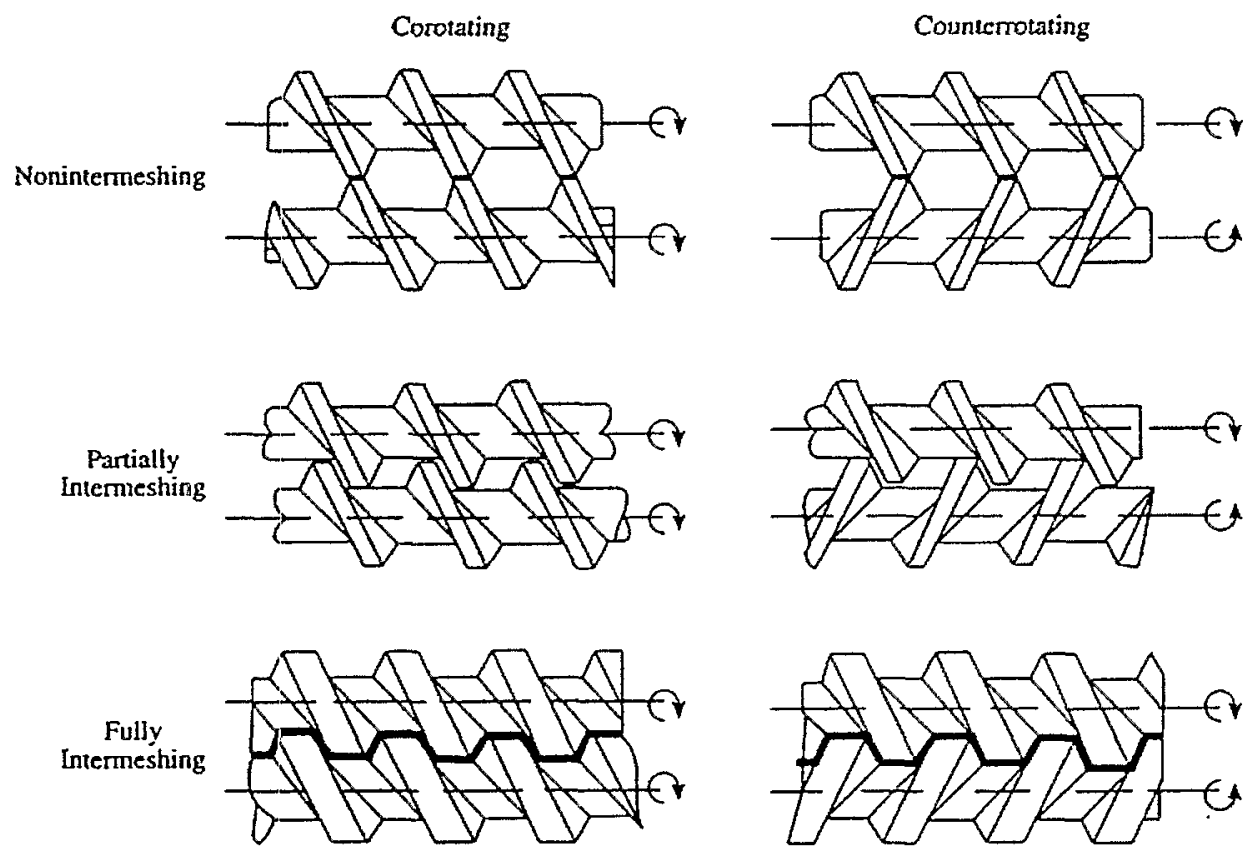

FIGURE 6.5.6 Types of screw configurations for twin-screw extruders.

"free liquids." As a consequence, higher moisture contents or wastes containing freestanding (unsorbed) liquids are difficult to process because the liquids tend to leak before being volatilized. The robust mixing action of kinetic mixers can also provide effective size reduction for wastes with larger particle sizes (e.g., $>2 \mathrm{~mm}$ ) that cannot be microencapsulated by extrusion. For example, pieces of failed cement grout waste forms (up to $19 \mathrm{~mm}$ in diameter) have been reprocessed by polyethylene microencapsulation using a kinetic mixer. The larger chunks of grout are broken down by the action of the high-shear rotor and frictional force of the polymer beads. The homogeneously mixed molten product is then discharged, allowed to cool, forming a leach-resistant waste form. Finally, the design of the kinetic mixer permits varying polymer type with only minor operational changes. Therefore, different recycled plastics can be easily substituted and comingled with little or no impact on the ability to process (Lageraaen and Kalb, 1997).

\section{Ancillary Process Equipment}

As with any $\mathrm{S} / \mathrm{S}$ process, ancillary equipment is required to pretreat the waste if necessary, deliver the waste to the processing equipment (materials handling), meter the waste and binder materials to the process vessel, collect and treat any secondary off-gases that are generated, and monitor and control critical parameters. These components, as well as the types of processing devices described above, are generally "off-the-shelf" equipment and need only be properly sized and specified before being assembled to form an integrated processing system. Waste and binder materials can be accurately metered by means of volumetric feeders, or more precisely by loss-in-weight feeders. Computer-controlled loss-in-weight systems can be set to operate at a predetermined mixture ratio, with accuracies of $\pm 0.5 \%$. Process controls and monitoring can be integrated and controlled remotely by computer. For example, BNL's productionscale microencapsulation process monitored output rate through a solid-state scale and then maintained feed rates at optimal levels through computerized process control feedback. A transient infrared spectroscopy (TIRS) online monitoring system was developed by Ames Laboratory to provide real-time information on the actual waste loadings being processed, thus improving overall quality assurance (Wright et al., 1994). 


\section{Polymer Selection}

Polyethylene is a relatively new engineering material. It was originally developed in 1933, with the first production-scale process capability emerging in 1939. Initial demand for the material was for cable insulation during World War II. Since then, continuous product improvements, coupled with expanding industrial applications, have made polyethylene the most widely used of all plastics today. Current production capacity in the United States alone is about 7 billion pounds annually (McGraw Hill, 1989).

As discussed in Chapter 6.1 , low-density $\left(0.914\right.$ to $\left.0.925 \mathrm{~g} / \mathrm{cm}^{3}\right)$ polyethylenes (LDPE) have lower melting and processing temperatures (typically $120^{\circ} \mathrm{C}$ and $150^{\circ} \mathrm{C}$, respectively) than high-density polyethylenes (typically $180^{\circ} \mathrm{C}$ and $200^{\circ} \mathrm{C}$, respectively). Polyethylenes are also available in a wide range of molecular weights, which are inversely proportional to their melt viscosity, or ability to flow while molten. The measure of melt viscosity is known as melt index, which describes how well the material flows (in units of $\mathrm{g} / 10 \mathrm{~min}$ ) under conditions specified by the American Society of Testing and Materials (ASTM) (ASTM D-1238, 1990). Thus, high-melt index plastics exhibit low-melt viscosities. LDPE is commercially available with melt indices ranging from 0.2 to $60 \mathrm{~g} / 10 \mathrm{~min}$. Mechanical properties (e.g., strength and durability) are generally better for high-molecular-weight (low melt index) polymers. Thus, selection of the optimal melt index plastic for microencapsulation is a balance between ease of processing while incorporating high waste solids loadings, and final product performance (Kalb and Colombo, 1984).

One distinct advantage for polyethylene microencapsulation compared with other $S / S$ alternatives is that many modern plastics, including polyethylene, are routinely recycled both at industrial and postconsumer levells. Because it is difficult to maintain aesthetic propertics (c.g., color) for recycled plastics, the commercial market for these materials is currently underdeveloped. However, recycled polyethylenes have potential for use as a microencapsulation waste binder because aesthetics is not a concern. A study conducted to evaluate issues of processibility and impact on final waste form performance found little effect due to use of recycled polyethylene as opposed to virgin materials (Lageraaen et al., 1997). However, supplies of well-characterized, homogeneous, recycled polyethylene are limited because commingling of different types of plastics during post-consumer collection is a common practice. Due to their varying properties, commingled plastics are more difficult to process. In such cases, mixing of virgin and recycled polyethylene resulted in superior processing performance.

\section{Pretreatment Requirements}

Because polymer microencapsulation does not rely on a chemical reaction for solidification, it is not susceptible to chemical interactions with the waste that can adversely impact other $S / S$ alternatives. However, physical properties of the waste, such as particle size and distribution, density, and moisture or other volatiles can affect processing, sometimes requiring pretreatment steps to ensure success.

Plastics extruders can generally handle waste particles in the 50- to 2000- $\mu \mathrm{m}$ size range. Smaller, lowdensity particles tend to "float" on the viscous polymer and resist homogeneous mixing. Larger particles are restricted due to clearances between the screw and barrel. These difficulties can sometimes be overcome through use of higher melt index (lower melt viscosity) polymers, pretreating fine particles by agglomeration, and grinding or size-reducing large particles.

Wastes with moisture or VOC contents $>2 \mathrm{wt} \%$ can be pretreated by the use of indirectly heated vacuum dryers, spray dryers, wiped film evaporators, or other suitable technique. The final product from any pretreatment process must not only meet process specifications for maximum volatiles content, but particle size requirements as well. Spray dryers tend to produce a particle size distribution skewed to the low end $(\leq 50 \mu \mathrm{m})$, whereas vacuum dryers may produce a product containing large agglomerated clumps that require size reduction. Kinetic mixers can also be used to pretreat wastes with excessive volatiles by discharging the waste-polymer mixture prior to complete fluxing (Kalb et al., 1997). This mixture of polymer and dried waste is then fed to an extruder for final processing. With proper coordination, this approach converts the process from a batch method to a continuous one. 
Hydrated ion exchange resins containing 40 to $60 \mathrm{wt} \%$ moisture require drying prior to microencapsulation. This causes the beads to shrink. Upon exposure to saturated conditions, the re-swelling of ion exchange resin beads within a microencapsulated waste form can cause the waste form to expand and even crack. This condition can be ameliorated by reducing the resin waste loading to $30 \mathrm{wt} \%$ or less or by thermal pretreatment of the beads to eliminate their ability to swell.

\section{Macroencapsulation}

Polyethylene macroencapsulation provides a suitable alternative for treatment of mixed waste lead or debris (particle sizes $>60 \mathrm{~mm}$ ). Such wastes include lead shielding contaminated equipment, drums, metal scraps and shavings, dismantlement and decommissioning residuals, laboratory or process trash, previously treated waste, or failed waste form products. These wastes are compacted or consolidated and then placed in a larger mold, drum, or container that is subsequently surrounded by a layer of clean molten plastic. Once the molten plastic cools, it forms a durable physical barrier that contains the waste and helps isolates contaminants from the environment. The thickness of the polymer layer can vary, but is typically 1 to 2 in. Single-screw extrusion is ideally suited for macroencapsulation because it can readily deliver a steady flow of molten polymer. With technology transfer assistance from the DOE and BNL, Envirocare of Utah, Inc., has successfully commercialized polyethylene macroencapsulation processing.

\section{Formulation Optimization}

As with other S/S technologies, optimization of waste matrix formulations is a balance between economic efficiency (i.e., optimal waste loading per unit volume) and final waste form performance (i.e., meeting regulatory and disposal site performance criteria). For polyethylene microencapsulation, waste chemistry is not a limiting factor, but the mixed waste's physical properties do limit the amount of waste that can be effectively mixed in the viscous polymer. When maximum waste loading is exceeded during extrusion, the melt pressure, amperage load, and mechanical wear increase. In the extreme, the extruder screw can become jammed if insufficient polymer is available for processing. If this occurs, feeding of pure polyethylene or a polymer purging compound usually corrects the problem. When maximum waste loading is exceeded during kinetic mixing, insufficient frictional energy is available to melt the polymer, thus significantly increasing process time and resulting in discharge of unencapsulated waste. Regardless of which processing technique is used, contaminants are more readily mobile through leaching or dispersion if the waste is not adequately encapsulated. For soluble wastes, leaching is usually directly proportional to the waste loading, until a break point is reached in which the individual waste particles are inadequately coated and a dramatic increase in leachability can be observed. For most dry solid wastes (e.g., dried evaporator salts, incinerator ash, soil) loadings between 50 and $70 \mathrm{dry} w \mathrm{t} \%$ waste can be achieved by polyethylene microencapsulation while still meeting the minimum leaching criteria established by both the NRC and EPA. By comparison, maximum equivalent loadings in hydraulic cement are typically 10 to 30 dry wt\%.

\section{Final Waste Form Performance}

Performance criteria for final waste forms depend on the generator (commercial vs. Department of Energy); type of waste (radioactive, hazardous, or mixed waste); and the disposal sites' waste acceptance criteria (WAC) and performance criteria. As mandated by the NRC in 10 CFR 61, all commercial lowlevel radioactive or mixed waste characterized as greater than Class $A$ (based on isotope-specific activity levels) must be either solidified or packaged in a licensed high-integrity container (HIC) for disposal (U.S. NRC, 1991). Specific testing protocol and performance criteria for solidified final waste forms are identified by NRC or disposal sites to establish long-term stability and immobilization of contaminants. These include leachability, mechanical integrity, resistance to biodegradation, radiation damage, freezethaw, and saturated soil conditions. As discussed, the performance of polyethylene microencapsulated waste forms has been shown to exceed these minimum performance standards. 


\section{Leachability}

Assuming long-term durability is established, leaching is the most important final waste form performance metric because it quantifies the ability of the waste form to isolate contaminants from the environment. Depending on the type of waste, several leach tests are commonly used to evaluate waste form leachability. The NRC recommends testing using ANS 16.1 protocol developed by the American Nuclear Society (ANS), which is designed to evaluate releases of contaminants in demineralized water under controlled conditions (ANS 16.1, 1986). This test provides a relative measure of leachability expressed as the leaching index, which is inversely proportional to the log of effective diffusivity. Thus, an incremental increase in the leaching index is equivalent to an order of magnitude reduction in leaching. Table 6.5.1 presents leach data results for sodium nitrate waste microencapsulated in polyethylene. For polyethylene microencapsulated waste forms, leachability is generally diffusion controlled and inversely proportional to the waste loading. Leach indices range from slightly more than 11 (30 wt\% loading) to just under 8 ( $70 \mathrm{wt} \%$ loading). For comparison, these results are between almost 2 and more than 5 orders of magnitude better than the minimum leach index of 6.0 recommended by the NRC for final waste forms containing low-level wastes. These data reflect the relatively low leachability of polyethylene waste forms and clearly show the direct relationship of waste loading and leach rate for soluble salt wastes encapsulated in polyethylenc.

TABLE 6.5.1 ANS 16.1 Leach Test Data for Sodium Nitrate Waste Microencapsulated in Polyethylene

\begin{tabular}{cccc}
\hline $\begin{array}{c}\mathrm{NaNO}_{3} \\
\begin{array}{c}\text { Waste Loading, } \\
\text { (wt\%) }\end{array}\end{array}$ & $\begin{array}{c}\text { Cumulative } \\
\text { Fraction } \\
\text { Leached of Na }\end{array}$ & $\begin{array}{c}\text { Diffusion } \\
\text { Coefficient } \\
\left(\mathrm{cm}^{2} / \mathrm{s}\right)\end{array}$ & $\begin{array}{c}\text { Leach } \\
\text { Index }\end{array}$ \\
\hline 30 & 0.9 & $8.4 \times 10^{-10}$ & 11.1 \\
50 & 6.3 & $6.0 \times 10^{-4}$ & 9.7 \\
60 & 15.0 & $1.1 \times 10^{-h}$ & 9.0 \\
70 & 73.4 & $1.5 \times 10^{--}$ & 7.8 \\
\hline
\end{tabular}

The Accelerated Leach Test (ALT), an alternative method recently approved by the American Society of Testing and Materials (ASTM C-1308), is, like ANS 16.1, a semi-dynamic test in distilled water with leachate replacement at regular intervals (ASTM C-1308, 1996). Several improvements (e.g., accelerated testing at elevated temperatures, computer analysis/modeling of data) have enabled the determination of leaching mechanisms and prediction of long-term leaching behavior. Actual leach data is compared with predicted diffusion-controlled releases and a goodness-of-fit is established. If the actual data fits the predicted model results, then the diffusion equation can be used to extrapolate the leaching of actual final waste forms over time. Accelerated Leach Testing of sodium nitrate waste microencapsulated in polyethylene confirmed that diffusion is the predominant leaching mechanism. Predicted releases as a function of waste loading are shown in Table 6.5.2. Projected cumulative fractional contaminant releases after 300 years from a full-sized waste form ( $2 \mathrm{~m}$ in diameter by $2 \mathrm{~m}$ in height), under worst-case fully saturated conditions, range from 3.7 to $9.5 \%$.

Wastes containing hazardous components defined by the EPA under the Resource Conservation and Recovery Act (RCRA), or a combination of hazardous and radioactive components (i.e., mixed wastes), must meet leaching criteria established in 40 CFR 61 (known at the Toxicity Characteristic Leaching Procedure, or TCLP). This is a very short-term $(18 \mathrm{hr})$ test designed to mimic conditions at a typical landfill to try and determine contaminant concentrations if the waste was not segregated and was disposed of at a conventional Subtitle $\mathrm{C}$ landfill. For example, the leachant is an acetic acid that is typically produced at landfills from the degradation of organic materials. TCLP was originally designed assuming treatment by a chemical stabilization method or by conventional grout $S / S$ that would eventually lose mechanical integrity and disintegrate. In other words, no credit is allowed for physical microencapsulation of the waste. The procedure requires passing the testing material through a $9.5-\mathrm{mm}$ sieve. If the material is a

monol

Becau:

under

ments,

represc

operati

Enviro

pH-ba:

additiv

system:

ditions

wastes

forms $i$

Sumr

Polyeth provide the mo: Macroe in a lay" leachab of wast loading virgin $\mathrm{F}$ technol. of mixe

Defini

Microe

\section{a}

pi

ac

Macroes

$\mathrm{m}$

fo

ar

Thermo

ac 
TABLE 6.5.2 Projected Releases from a ProductionScale Polyethylene Microencapsulated Waste Form Following 300 years Leaching under Fully Saturated Conditions

\begin{tabular}{ccc}
$\begin{array}{c}\mathrm{NaNO}_{3} \\
\text { Waste Loading, } \\
(\mathrm{wt} \%)\end{array}$ & $\begin{array}{c}\text { Diffusion } \\
\text { Coefficient, } \\
\left(\mathrm{cm}^{2} / \mathrm{s}\right)\end{array}$ & $\begin{array}{c}\text { Projected Cumulative } \\
\text { Fraction Leached, } \\
(\%)\end{array}$ \\
\hline 50 & $3.05 \times 10^{-4}$ & 3.7 \\
60 & $8.6 \times 10^{-4}$ & 5.0 \\
70 & $5.58 \times 10^{-4}$ & 9.5 \\
\hline
\end{tabular}

monolithic solid, it is size-reduced so that pieces of the monolith that fit through the sieve are tested. Because polyethylene microencapsulation is a durable final waste form that is not expected to degrade under disposal conditions, a modified preparation procedure was developed to meet TCLP size requirements, without sacrificing the integrity of the encapsulation. Pellets that fit through the $9.5-\mathrm{mm}$ sieve, representing miniature waste forms, are cast and tested. This modified procedure is described in the operational permit for polyethylene microencapsulation, approved by the State of Utah Department of Environmental Conservation, Division of Hazardous Waste. The TCLP test is also biased toward alkaline $\mathrm{pH}$-based systems because the leachant is slightly acidic and can be easily neutralized by highly alkaline additives. And because the solubility of most toxic metals is limited under high $\mathrm{pH}$ conditions, these systems resist leaching under the short-term test conditions but are not evaluated over long-term conditions. The EPA is currently examining alternatives to TCLP; but until another test is specified, all treated wastes must still meet these criteria. Results from TCLP leaching of polyethylene microencapsulated waste forms is summarized in Table 6.5.3.

\section{Summary}

Polyethylene encapsulation is a physical process to treat radioactive, hazardous, and mixed wastes that provides good, long-term stability and low leaching. Microencapsulation combines waste particles with the molten polymer to form a homogeneous mixture that results in a solid final waste form on cooling. Macroencapsulation, used for contaminated lead or other debris (particles $>60 \mathrm{~mm}$ ), surrounds the waste in a layer of clean plastic that provides mechanical integrity, reduces potential for intrusion, and lowers leachability. Because no chemical reaction is required for this process, it is compatible with a wide range of wastes, is insensitive to waste chemistry, and results in final waste forms with relatively high waste loadings (e.g., 50 to $70 \mathrm{wt} \%$ of dry waste). Recycled polyethylene can be successfully used in place of virgin plastics, providing a market for this valuable resource and reducing the overall process costs. The technology has been deployed at production scale and is currently commercially available for treatment of mixed wastes.

\section{Defining Terms}

Microencapsulation: Thorough and homogeneous mixing of small waste particles (i.e., $<60 \mathrm{~mm}$ ) with a liquid binder that then solidifies to form a solid, monolithic final waste form. Individual waste particles are coated and surrounded by the solidified binder to provide mechanical integrity and act as a barrier against leaching of contaminants.

Macroencapsulation: Packaging large pieces of waste (i.e., $>60 \mathrm{~mm}$ ) not suitable for processing by microencapsulation and surrounding the package with a layer of clean binder material. The binder forms a protective layer around the waste that provides structural support, prevents dispersion, and helps reduce migration of contaminants.

Thermosetting polymers: Polymers that require a chemical polymerization reaction (through the interaction of monomer, catalyst, and promoter) to form a hardened, monolithic, solid product. 
Polyethylene Encal

TABLE 6.5.3 Toxicity Characteristic Leaching Procedure Data for Polyethylene Microencapsulated Waste Forms

Toxic Metal Source Term Conc. ${ }^{3}$

(Microencapsulated Waste Form TCLP Concentration) (ppm)

\begin{tabular}{|c|c|c|c|c|c|c|c|}
\hline & & & & & & & \\
\hline Waste Stream & $\begin{array}{l}\text { Waste Loading } \\
\text { (wt\%) }\end{array}$ & $\mathrm{Pb}$ & $\mathrm{Cr}$ & $\mathrm{Cd}$ & $\mathrm{Hg}$ & Se & As \\
\hline DOE mixed salts & 60 & $\begin{array}{c}3000 \\
(0.07)\end{array}$ & $\begin{array}{c}3000 \\
(0.10)\end{array}$ & $\begin{array}{c}3000 \\
(0.37)\end{array}$ & & & \\
\hline DOE incinerator ash & 60 & $\begin{array}{c}5000 \\
(0.01)\end{array}$ & $\begin{array}{c}5000 \\
(0.01)\end{array}$ & $\begin{array}{c}5000 \\
(0.01)\end{array}$ & & & \\
\hline SRS CIF blowdown & 40 & $\begin{array}{l}2250 \\
(<0.05)\end{array}$ & $\begin{array}{c}500 \\
(0.07)\end{array}$ & $\begin{array}{c}125 \\
(<0.05)\end{array}$ & $\begin{array}{c}250 \\
(<0.04)\end{array}$ & & \\
\hline INEEL carbonate salt & 50 & $\begin{array}{c}120 \\
(<0.14)\end{array}$ & & & & & \\
\hline INEEL ion exchange resin & 40 & $\begin{array}{l}1200 \\
(1.6)\end{array}$ & & & & & \\
\hline $\begin{array}{l}\text { INEEL sodium bearing } \\
\text { waste }\end{array}$ & 40 & $\begin{array}{c}218 \\
(<0.14)\end{array}$ & $\begin{array}{c}351 \\
(2.4)\end{array}$ & $\begin{array}{c}246 \\
(0.34)\end{array}$ & $\begin{array}{c}242 \\
(<0.0002)\end{array}$ & & \\
\hline $\begin{array}{l}\text { Commercial incinerator } \\
\text { ash }\end{array}$ & 50 & & & & & $\begin{array}{c}15 \\
(<0.15)\end{array}$ & \\
\hline $\begin{array}{l}\text { Molten salt oxidation } \\
\text { residuals }\end{array}$ & 50 & & $\begin{array}{l}2400 \\
(1.6)\end{array}$ & & & & \\
\hline Fernald Silo lsludge & 50 & $(0.712)$ & & & & & \\
\hline Fernald Silo 3 sludge & 60 & $(0.058)$ & $(0.029)$ & $(0.002)$ & & $(0.088)$ & $(0.245)$ \\
\hline $\begin{array}{l}\text { Maximum allowable } \\
\text { concentration, TCLP }\end{array}$ & & 5.0 & 5.0 & 1.0 & 0.2 & 1.0 & 5.0 \\
\hline $\begin{array}{l}\text { Maximum allowable } \\
\text { concentration, UTS }\end{array}$ & & 0.75 & 0.85 & 0.2 & 0.025 & 5.7 & 5.0 \\
\hline
\end{tabular}

" Toxic metal concentration in the waste, i.e., source term.

"EPA is phasing in new Universal Treatrient Standards (UTS) with lower allowable concentrations for toxic metals.

Thermoplastic polymers: Polymers with a linear molecular structure that repeatedly melt to a flowable state when heated and then harden to a solid when cooled.

Melt index: A measure of the relative flowability of plastic resins while molten. The value is quantified by application of a standard test method (ASTM D-1238) that specifies the temperature and flow conditions using a plastics rheometer. The units are given in $\mathrm{g} / 10 \mathrm{~min}$.

\section{References}

American National Standards Institute/American Nuclear Society (ANS), 1986. Standard for Measurement of the Leachability of Low-Level Radioactive Wastes by Short-Term Procedure, ANS 16.1.

American Society of Testing and Materials (ASTM), 1990. ASTM Standard Test Method for Flow Rates of Thermoplastics by Extrusion Plastomer, ASTM D-I238. American Society of Testing and Materials, West Conshohocken, PA.

American Society of Testing and Materials (ASTM), 1996. Standard Method of Test for Accelerated Leach for Diffusive Releases from Solidified Waste and a Computer Program to Model Diffusive, Fractional Leaching from Cylindrical Waste Forms, ASTM C-1308. American Society of Testing and Materials, West Conshohocken, PA.

Colombo, P., Barth, E., Bishop, P., Buelit, J., and Conner, J.R., 1994. Innovative site remediation technology, stabilization/solidification, in WASTECH Series, Volume 4,W.C. Anderson, Ed., American Academy of Environmental Engineers, Annapolis, MD.

Colombo, P., Kalb, P.D., and Fuhrmann, M., 1983. Waste Form Development Program Annual Report, BNL-51756. Brookhaven National Laboratory, Upton, NY.
Faucette, A.M., Log: wastes at the Management

Fuhrmann, M. and Stabilization ، STP 1240, T.A

Kalb, P.D., 1993. Po BNL-49738. 1

Kalb, P.D. and Colo Radioactive, (March 24, 1'

Kalb, P.D. and Colo 51867. Brool

Kalb, P.D. and Colk BNL-33404.

Kalb, P.D., Conner remediation Vol. 4, W.C.

Kalb, P.D., Cowgill and Treatm

Kalb, P.D., Heiser of low-level Managemen Chemical S

Kalb, P.D., Heiser, Form Stabi Brookhaver

Kalb, P.D., Lagera: system for Tucson, Az

Kalb, P.D., Lager: encapsulat A31:1767-

Lageraaen, P.R. 2 ardous, an NY.

Lageraaen, P.R., Polymer Brookhav,

Lageraaen, P.R., Encapsulc Upton, N

Modern Plastics

Patel, B.R., Lag Encapsul: Upton, $\mathrm{N}$

U.S. Nuclear R Waste, in

U.S. Nuclear Re Classifice 
Faucette, A.M., Logsdon, B.A., Lucerna, J.J., and Yudnich, R.J., 1994. Polymer solidification of mixed wastes at the rocky flats plant. in Proceedings of the Symposium on Waste Management, Waste Management '94, Vol. 3, R.G. Post, Ed., Tucson, AZ.

Fuhrmann, M. and Kalb, P.D., 1996. Leaching behavior of polyethylene encapsulated nitrate waste. in Stabilization and Solidification of Hazardous, Radioactive and Mixed Wastes, 3rd volume, ASTM STP 1240, T.M. Gilliam and C.W. Wiles, Eds., American Society of Testing and Materials.

Kalb, P.D., 1993. Polyethylene Encapsulation of Simulated Blowdown Waste for SEG Treatability Study, BNL-49738. Brookhaven National Laboratory, Upton, NY.

Kalb, P.D. and Colombo, P., 1999. Composition and Process for the Encapsulation and Stabilization of Radioactive, Hazardous, and Mixed Wastes. U.S. Patent Nos. 5,649,323 (July 1997); 5,732,364 (March 24, 1998); and 5,926,772 (July 20, 1999).

Kalb, P.D. and Colombo, P., 1984. Polyethylene Solidification of Low-Level Wastes, Topical Report, BNL51867. Brookhaven National Laboratory, Upton, NY.

Kalb, P.D. and Colombo, P., 1983. Selection of Improved Solidification Agents for Further Investigation, BNL-33404. Brookhaven National Laboratory, Upton, NY.

Kalb, P.D., Conner, J.R., Mayberry, J.L., Patel, B.R., Perez, J.M., and Treat, R.L. ,1997. Innovative site remediation technology design and application, Stabilization/Solidification., in WASTECH Series, Vol. 4, W.C. Anderson, Ed., American Academy of Environmental Engineers, Annapolis, MD.

Kalb, P.D., Cowgill, M.G., Milian, L.W., and Selcow, E.C., 1995. BNL Building 650 Lead Decontamination and Treatment Feasibility Study, BNL- 64383. Brookhaven National Laboratory, Upton, NY.

Kalb, P.D., Heiser J.H., and Colombo P., 1993. Long-term durability of polyethylene for encapsulation of low-level radioactive, hazardous, and mixed wastes, in Energing Technologies in Hazardous Waste Management III, ACS Symposium Series No. 518, D.W. Tedder and F.G. Pohland, Eds., American Chemical Society.

Kalb, P.D., Heiser, J.H., and Colombo, P., 1991. Polyethylene Encapsulation of Nitrate Salt Wastes: Waste Form Stability, Process Scale-up, and Economics - Technology Status Topical Report, BNL 52293. Brookhaven National Laboratory, Upton, NY.

Kalb, P.D., Lageraaen, P.R., Patel, B.R., Sangster, D.C., and Poste, A., 1997. Development of a pretreatment system for polyethylene encapsulation of mixed wastes, in Proceedings of Waste Management '97, Tucson, AZ.

Kalb, P.D., Lageraaen, P.R., and Wright, S., 1996. Full-scale technology demonstration of a polyethylene encapsulation process for radioactive, hazardous, and mixed wastes, J. Environ. Sci. \& Health, A31:1767-1780.

Lageraaen, P.R. and Kalb, P.D., 1997. Use of Recycled Polymers for Encapsulation of Radioactive, Hazardous, and Mixed Wastes - Final Report, BNL-66575. Brookhaven National Laboratory, Upton, NY.

Lageraaen, P.R., Kalb, P.D., Milian, L.W., and Adams, J.W., 1997. Development and Demonstration of Polymer Microencapsulation of Mixed Waste Using Kinetic Mixer Processing, BNL-66576. Brookhaven National Laboratory, Upton, NY.

Lageraaen, P.R., Patel, B.F., Kalb, P.D., and Adams, J.W., 1995. Treatability Studies for Polyethylene Encapsulation of INIEL Low-Level Mixed Wastes, BNL-62620. Brookhaven National Laboratory, Upton, NY.

Modern Plastics Encyclopedia, 1989, McGraw Hill Publishers, New York.

Patel, B.R., Lageraaen, P.K., and Kalb, P.D., 1995. Review of Potential Processing Techniques for the Encapsulation of Waste in Thermoplastic Polymers, BNL-62200. Brookhaven National Laboratory, Upton, NY.

U.S. Nuclear Regulatory Commission, 1983. Licensing Requirements for Land Disposal of Radioactive Waste, in Title 10 of the Code of Federal Regulations, Part 61. USNRC, Washington, D.C.

U.S. Nuclear Regulatory Commission, 1991. Technical Position on Waste Form, Revision 1, in Final Waste Classification and Waste Form Technical Position Papers. USNRC, Washington, D.C. 
Werner and Pfleiderer Co., 1976. Topical Report: Radwaste Volume Reduction and Solidification System, Report No. WPC-VRS-1. Waldwick, NJ.

Wright, S.L., Jones, R., McClelland, J.F., and Kalb, P.D., 1994. Preliminary test of an integrated process monitor for polyethylene encapsulation of radioactive waste, in Stabilization and Solidification of Hazardous, Radioactive, and Mixed Wastes, ASTM STP 1240, T.M. Gillian and C.C. Wiles, Eds., Philadelphia, PA.

\section{For Further Information}

Two volumes of the Innovative Site Remediation Technology series, published by the American Academy of Environmental Engineers, contain useful information about polymer stabilization/solidification technologies. Each of these books compares polymer technologies with conventional hydraulic cement S/S technologies, as well as other innovative processes such as vitrification. The first series, entitled "Stabilization/Solidification" (Colombo et al., 1994) presents a broad overview of the technologies, process descriptions, potential applications, process evaluations, and limitations of the technologies. The second edition, entitled "Stabilization/Solidification Design and Application" (Kalb et al., 1997b) provides more specific information required for technology deployment, including application concepts (e.g., principles, applications, treatment trains), design development (e.g., design basis, equipment selection, pre- and post-treatment processes, instrumentation/controls, safety, permitting, performance measures), and implementation/operation (e.g., start-up, operational, and maintenance procedures). 